\title{
Influence of the vagus nerve upon the reflex control of the lower oesophageal sphincter
}

\author{
A L OGILVIE* AND M ATKINSON \\ From University Hospital, Queen's Medical Centre, Nottingham
}

SUMmARY In 24 control patients the lower oesophageal sphincter responded to graded increments in intra-abdominal pressure by a significant and sustained rise in tone. This response was abolished by atropine and was also absent in nine of 11 patients who had previously undergone truncal vagotomy for duodenal ulcer but not in the remaining two who had recurrent ulceration. In six patients studied after proximal gastric vagotomy a variable response was seen. Gastric efferent vagal function was assessed by a combined insulin/pentagastrin gastric secretory test and did not correlate closely with the lower oesophageal sphincteric response to increased intra-gastric pressure. These findings are explicable if it is assumed that truncal vagotomy interrupts the afferent limb of a reflex arc regulating lower oesophageal sphincteric tone.

Lower oesophageal sphincter pressure has been shown to increase with a rise in intra-abdominal pressure $^{12}$ and this may represent an important mechanism protecting against gastro-oesophgeal reflux. Whether the vagus nerve is concerned in the reflex control of the lower oesophageal sphincter is uncertain and while some have found that truncal vagotomy abolishes the sphincteric response to increase in intra-abdominal pressure, ${ }^{34}$ others have failed to do so and have suggested the pressure increase is brought about by diaphragmatic contraction. ${ }^{5}$

To investigate the possible role of the vagus in the reflex control of the lower oesophageal sphincter, we have studied the effects of atropine and of truncal and proximal gastric vagotomy upon the response of the lower oesophageal sphincter to increase in intra-abdominal pressure.

\section{Methods}

\section{PATIENTS}

The control group consisted of 24 patients ( 21 men) with a mean age of 43 years (range 30-70 years), who had undergone upper gastrointestinal fibreoptic endoscopy for dyspepsia. Eighteen had chronic

Address for correspondence: Dr M Atkinson, University Hospital, Queens Medical Centre, Nottingham NG7 2UH

Received for publication 21 June 1983

- Present address: Gastrointestinal Unit, Western General Hospital, Crewe Road, Edinburgh. duodenal ulcer and in six no abnormality was found. All patients were judged to be free of oesophageal disease after radiological, endoscopic, oesophageal mucosal biopsy, oesophageal motility, and oesophageal acid perfusion studies.

Eleven patients ( 10 men) with a mean age of 48 years, (range 34-62 years), who had undergone truncal vagotomy for chronic duodenal ulcer were studied. Two had recurrent duodenal ulcer and four had postvagotomy complications (biliary gastritis in two and reflux oesophagitis in two).

Six patients (five men) with a mean age of 43 years (range 23-54 years), who had undergone proximal gastric vagotomy were also studied. None of this group had evidence of recurrent duodenal ulceration.

The investigation was approved by the ethical committee and all patients gave their informed consent to take part.

\section{MEASUREMENT OF LOWER OESOPHAGEAL}

SPHINCTER PRESSURE

The pressures were recorded through a triple lumen polyvinyl tube (outer diameter $3.5 \mathrm{~mm}$, inner diameter of each lumen $1 \mathrm{~mm}$ ) which had three lateral orifices situated at the same horizontal level and radially orientated at intervals of $120^{\circ}$. Each lumen was perfused with water at a rate of $0 \cdot 8$ $\mathrm{ml} / \mathrm{min}$ from a motor driven greased glass syringe and was connected via transducers to an ultraviolet recorder. The system had a maximum rate of 
response of $900 \mathrm{mmHg} / \mathrm{sec}$ and an accuracy over the range of 0 to $60 \mathrm{mmHg}$ of $\pm 2 \mathrm{mmHg}$. At the beginning of each study calibration was made against a column of mercury and the atmospheric pressure was recorded with the transducers placed horizontally at the level of the anterior axillary line.

Patients were studied fasting in the supine position. After a 15 minute resting period the level of the lower oesophageal sphincter was identified by withdrawing the tube in $1 \mathrm{~cm}$ steps and recording for 15 seconds at each level. The lower oesophageal sphincter pressure was then measured by the rapid pull through technique ${ }^{6}$ by withdrawing the tube through the previously identified sphincter at a rate of $1 \mathrm{~cm} / \mathrm{sec}$ with the patient holding his breath in expiration. Each reading of lower oesophageal sphincter pressure represented a mean of 15 values obtained by five pull throughs of the recording tube.

A thigh sphygmomanometer cuff was then bound to the anterior abdominal wall and inflated in increments of $10 \mathrm{mmHg}$ to a maximum of 100 $\mathrm{mmHg}$ or until the patient was unable to tolerate the pressure. At the end of the procedure the cuff was removed and resting lower oesophageal sphincter pressure was again recorded.

Intragastric pressure was taken as the difference between the fundal pressure and atmospheric pressure and the increase in intragastric pressure with abdominal compression was obtained by subtracting the resting intragastric pressure from the intragastric pressure recorded at each cuff pressure. Lower oesophageal sphincter pressure was taken as the difference between the maximum pressure in the sphincter and the intragastric pressure using the mean of 15 readings taken at each level of pressure in the abdominal cuff. The increase in intragastric pressure was not closely related to the level of pressure in the cuff and varied between individuals depending upon the resistance of the anterior abdominal wall. For this reason changes in lower oesophageal sphincter pressure were recorded in relation to changes in intragastric pressure rather than the indicated pressure in the cuff.

\section{GASTRIC SECRETORY STUDIES}

Gastric secretion was studied after an overnight fast. A phenol red marker was used to correct for collection errors and pyloric losses ${ }^{7}$ and electrolyte concentrations of gastric juice were measured to correct for swallowed saliva and duodenogastric reflux. ${ }^{8}$ The ratio of the peak acid output after insulin induced hypoglycaemia (blood sugar concentration less than $2 \mathrm{mmol} / \mathrm{l})$ to the maximal acid output after pentagastrin $(6 \mu \mathrm{g} / \mathrm{kg}$ body weight $)$ was used to assess the status of vagal efferent fibres to the stomach. ${ }^{9}$
STATISTICAL METHOD

The $t$ test for paired data was used to compare the lower oesophageal sphincter pressure measurements within individuals.

\section{Results}

\section{EFFECT OF ABDOMINAL COMPRESSION UPON} LOWER OESOPHAGEAL SPHINCTER PRESSURE In all groups there was a close correlation between the values of resting lower oesophageal sphincter pressure obtained before inflation of the abdominal cuff and those after its release $(r=0.9 ; p<0.001)$.

The mean resting intragastric pressure and the mean resting lower oesophageal sphincter pressure did not differ between the control patients and those who had undergone truncal vagotomy or proximal gastric vagotomy (Table). In the control group increase in intragastric pressure with abdominal compression resulted in a significant and sustained rise of lower oesophageal sphincter pressure (Fig. 1). The rise in lower oesophageal sphincter pressure was apparent with relatively small increases in intragastric pressure of up to $3 \mathrm{mmHg}$ and with further increases of intragastric pressure, lower oesophageal sphincter pressure rose proportionately less. Eight of the control patients were given atropine $(0.01 \mathrm{mg} / \mathrm{kg}$ body weight subcutaneously) and the study was repeated. Although the resting values of intragastric pressure and lower oesophageal sphincter pressure before and after atropine in these patients were comparable (Table) the lower oesophageal sphincter pressure response to increase in intragastric pressure was abolished by the drug (Fig. 2).

In those patients who had undergone truncal vagotomy, increase of intragastric pressure did not result in any increase in lower oesophageal sphincter pressure and indeed there was a tendency for this to fall (Fig. 3). Five of these patients were given

Table Mean resting intragastric pressure and mean resting lower oesophageal sphincter pressure in patients having undergone truncal vagotomy or proximal gastric vagotomy

\begin{tabular}{|c|c|c|c|}
\hline Group & $\begin{array}{l}\text { Patients } \\
\text { (no.) }\end{array}$ & $\begin{array}{l}\text { Resting } \\
\text { intra-gastric } \\
\text { pressure }(\mathrm{mmHg})\end{array}$ & $\begin{array}{l}\text { Resting lower } \\
\text { oesophageal } \\
\text { sphincter } \\
\text { pressure }(\mathrm{mmHg})\end{array}$ \\
\hline Controls & 24 & $9 \cdot 6 \pm 0 \cdot 79$ & $12 \cdot 3 \pm 0 \cdot 79$ \\
\hline pre-atropine & 8 & $9 \cdot 1 \pm 1 \cdot 78$ & $11 \cdot 0 \pm 0 \cdot 81$ \\
\hline postatropine & 8 & $9 \cdot 2 \pm 2 \cdot 08$ & $9.9 \pm 0.89$ \\
\hline Truncal vagotomy & 11 & $10 \cdot 0 \pm 0 \cdot 76$ & $11 \cdot 9 \pm 1 \cdot 55$ \\
\hline postcarbachol & 5 & $10 \cdot 4 \pm 0 \cdot 81$ & $19 \cdot 5 \pm 1 \cdot 83$ \\
\hline Proximal gastric & & & \\
\hline vagotomy & 6 & $10 \cdot 6 \pm 1 \cdot 34$ & $14 \cdot 0 \pm 1 \cdot 63$ \\
\hline
\end{tabular}


Fig. 1 Response of lower oesophageal sphincter (LOS) pressure to increasing intragastric pressure in 24 controls. Points are means $\pm S E M$. Dotted line indicates resting lower oesophageal sphincter pressure and significant changes are indicated $\left({ }^{*} p<0.01 ;{ }^{* *}\right.$ $p<0.001)$.

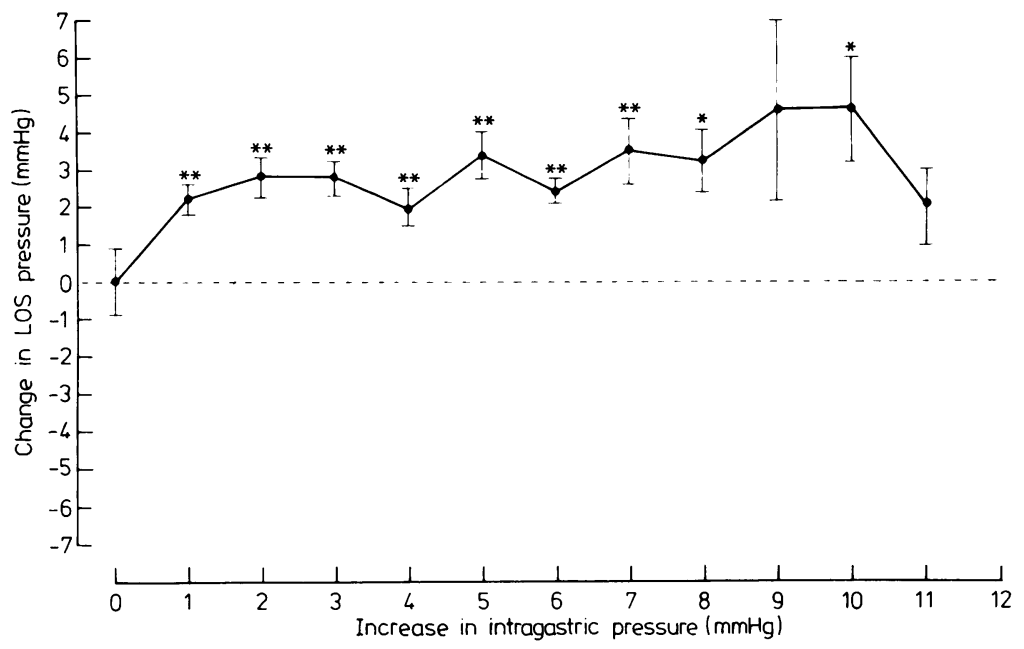

carbachol (4 $\mu \mathrm{g} / \mathrm{kg}$ body weight subcutaneously). Although carbachol caused a rise in the resting lower oesophageal sphincter pressure (Table) there was no further increase with abdominal compression.

In the six patients who had undergone proximal gastric vagotomy the change in lower oesophageal sphincter pressure with increasing intragastric pressure was variable and a rise was found in three of the six patients.

The rise in lower oesophageal sphincter pressure was not proportional to that of intragastric pressure and after an initial increase, lower oesophageal sphincter pressure tended to form a plateau as intragastric pressure was increased further, thus maintaining a relatively constant gradient between pressure in the stomach and that in the sphincter. To illustrate the variability between individual patients in each group the maximum rise of lower oesophageal sphincter pressure during abdominal compression is shown in Fig. 4. In the control group of patients this ranged from $2 \cdot 5-9 \mathrm{mmHg}$ but after atropine never exceeded $1.4 \mathrm{mmHg}$. In only two of the 11 patients who had undergone truncal vagotomy did the rise in lower oesophageal sphincter pressure lie within this range and these were the two patients with recurrent ulceration. In the other nine, lower oesophageal sphincter
Fig. 2 Effect of atropine on the lower oesophageal sphincter (LOS) pressure response to increasing intragastric pressure in eight controls. Points are means $\pm S E M$. The response before atropine is shown by $\Delta-\Delta$ and response after atropine by line represents resting lower oesophageal sphincter pressure and significant changes are indicated $\left({ }^{*} p<0.05 ; * *\right.$ $p<0.01)$.

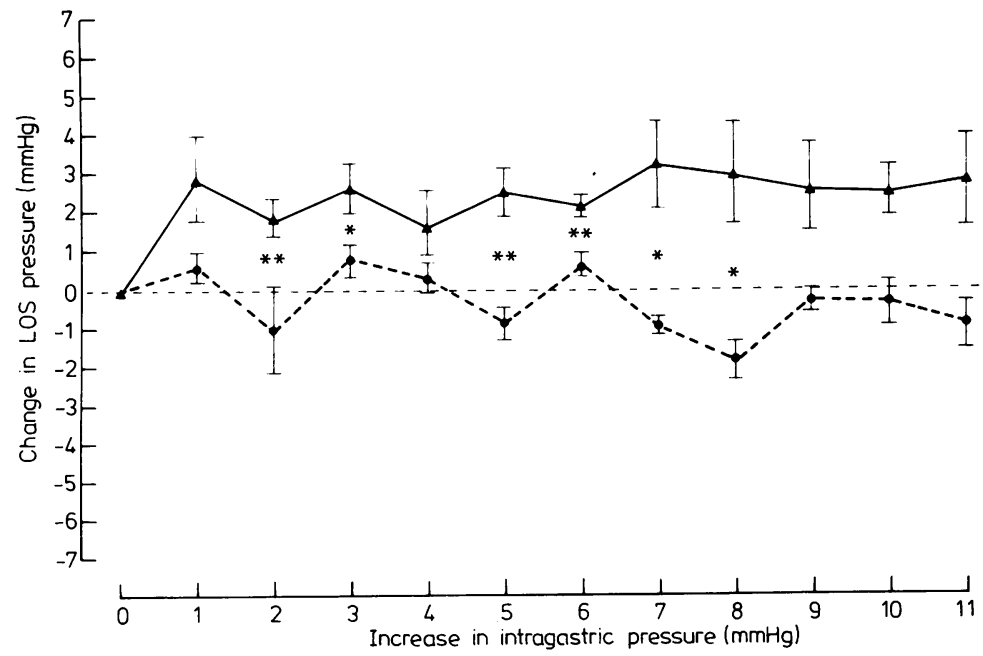


Fig. 3 Response of lower oesophageal sphincter (LOS) pressure to increasing intragastric pressure in 13 patients after truncal vagotomy. Points are means $\pm S E M$.

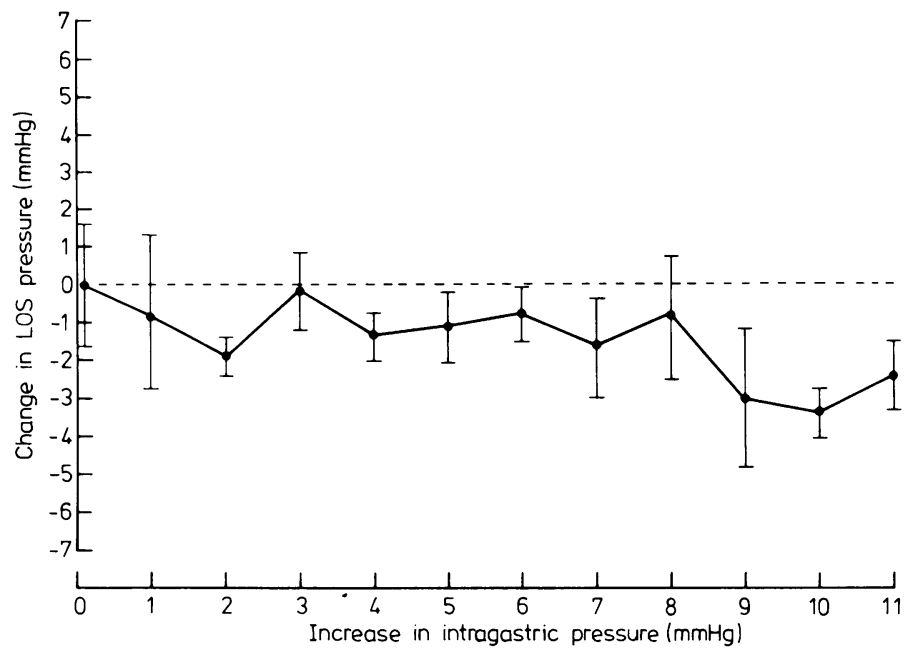

pentagastrin acid output ratio was 0.75 or greater. This figure was taken to indicate that the gastric vagal efferent supply was intact. Six patients after truncal vagotomy were studied and in all the insulin/pentagastrin ratio was less than 0.6 and this included two patients in whom duodenal ulceration had recurred. Five of the proximal gastric vagotomy group had ratios of less than 0.6 and the remaining patient gave a value of 0.73 .

In Fig. 5 the maximum change in lower

Gastric secretory studies were done in 10 of the control group of patients and in each the insulin/

pressure fell with abdominal compression. Of the six a three, lower oesophageal sphincter pressure fell during abdominal compression.

\section{GASTRIC SECRETORY STUDIES}

Fig. 4 Maximum change in mean lower oesophageal sphincter (LOS) pressure in the various groups studied. the solid horizontal line indicates the resting lower oesophageal sphincter pressure and the dotted horizontal line represents the lower limit of the normal response to increasing intragastric pressure.

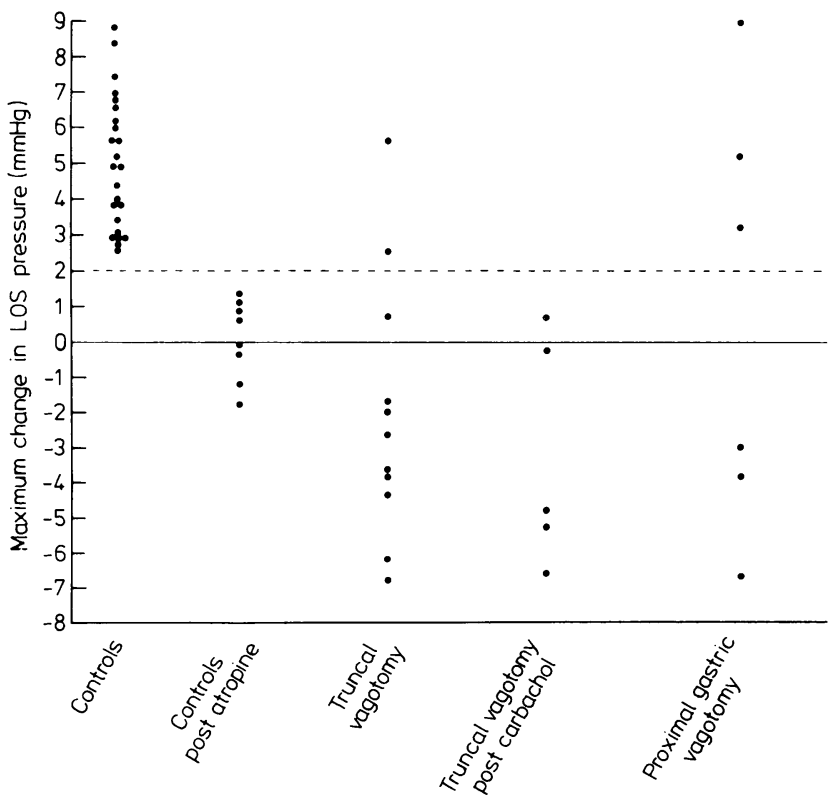


Fig. 5 Relationship between maximum change in lower oesophageal sphincter (LOS) pressure and insulin/ pentagastrin ratio. Controls are shown as $\Delta$, proximal gastric vagotomy as $\square$, truncal vagotomy without recurrent ulceration as $\bigcirc$ and truncal vagotomy with recurrent ulceration by . Dotted lines represent lower limits of normal for both tests.

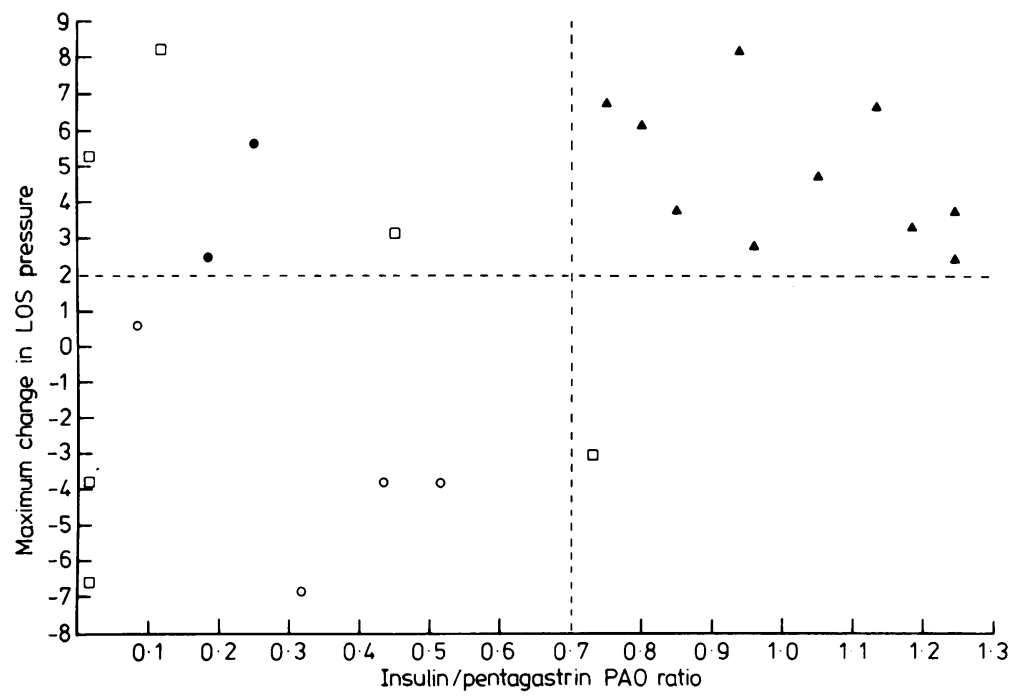

oesophageal sphincter pressure with abdominal compression is plotted against the insulin/ pentagastrin ratio and it will be seen that there is no simple linear correlation between the two. In all the control patients both tests were normal and it is of interest that in the two patients who developed recurrent duodenal ulcer after truncal vagotomy the maximal change in lower oesophageal sphincter pressure was within the normal range in spite of a low insulin/pentagastrin ratio in contrast with the remainder of this group in which both tests were abnormal. In the proximal gastric vagotomy group there was no correlation between the insulin/ pentagastrin ratio and the maximal change in lower oesophageal sphincter pressure.

\section{Discussion}

Our finding that the tone of the lower oesophageal sphincter normally increases with increase in intragastric pressure is in accordance with studies in which the station pull through technique was used. $^{134}$ Others using the rapid pull through technique, however, have failed to show such a response $^{10} 11$ and the discrepancy may be explained by differences in the technique used. We took multiple measurements of lower oesophageal sphincter pressure at each cuff pressure, increased the pressure in the cuff by small increments and plotted intragastric pressure rather than the pressure in the cuff itself against lower oesophageal sphincter pressure. The marked response to small changes in intragastric pressure and the fact that the response was abolished by atropine suggests that the pressure increase in the sphincter was because of sphincteric contraction and not to external mechanical forces such as a diaphragmatic contraction.

Truncal vagotomy does not alter the resting lower oesophageal sphincter pressure ${ }^{1213}$ and our finding that truncal vagotomy abolishes the response of the sphincter to increased intragastric pressure is in keeping with the work of others using the station pull through technique. ${ }^{34}$ The rise in lower oesophageal sphincter pressure after carbachol, found in patients with truncal vagotomy, indicates that the smooth muscle of the sphincter is capable of contracting when stimulated directly but fails to do so in response to increase of intragastric pressure suggesting interruption of the nervous pathways which mediate the sphincteric response. It is of interest that in patients studied after truncal vagotomy the presence of recurrent duodenal ulcer correlated better with the sphincteric response to intra-abdominal compression than it did with the insulin/pentagastrin gastric secretory ratio, suggesting that the response of the lower oesophageal sphincter to abdominal compression might form a valid test for the completeness of surgical vagotomy.

Our findings support the view that the response of the lower oesophageal sphincter to increased intraabdominal pressure is mediated by a vagovagal reflex, the efferent limb of which includes a muscarinic cholinergic pathway blocked by atropine. The normal lower oesophageal sphincter pressure values found after surgical vagotomy suggest that efferent vagal fibres to the lower oesophageal sphincter enter the oesophagus at a higher level than that of vagal section at surgery and reach the sphincter via the oesophageal plexus. Interruption of afferent vagal fibres from the 
abdomen, however, undoubtedly occurs at surgical truncal vagotomy and probably accounts for the lack of response of the lower oesophageal sphincter to abdominal compression after this procedure. Proximal gastric vagotomy in dogs does not abolish the sphincter response to abdominal compression ${ }^{14}$ but in our study only half of the patients showed a normal response. This may be due to a variable degree of interruption of afferent vagal fibres by proximal gastric vagotomy.

As the response of the lower oesophageal sphincter to increase in intra-abdominal pressure is dependent on both intact afferent and intact efferent vagal fibres we would suggest that it is a valid test of vagal function in the upper alimentary tract and may be of use in the investigation of autonomic neuropathy.

\section{References}

1 Lind JF, Warrian WG, Wankling WJ. Responses of the gastro-oesophageal junction zone to increases in intraabdominal pressure. Can J Surg 1966; 9: 32-8.

2 Cohen S, Harris LD. Does hiatus hernia affect competence of the gastro-oesophageal sphincter? $N$ Engl J Med 1971; 284: 1053-6.

3 Crispin JS, McIver DK, Lind JF. Manometric study of the effect of vagotomy on the gastro-oesophageal sphincter. Can J Surg 1967; 10: 299-303.

4 Angorn IB, Dimoupolos G, Hegarty MM, Moshal MG. The effect of vagotomy on the lower oesophageal sphincter: a manometric study. Br J Surg 1977; 64: 466-9.

5 Csendes A, Öster M, Brandsborg O et al. The effect of vagotomy on human gastro-oesophageal sphincter pressure in the resting state and following increases in intra-abdominal pressure. Surgery 1979; 85: 419-24.

6 Dodds WJ, Hogan WJ, Stef JJ, Miller WN, Lydon SB, Arndorfer RC. A rapid pull through technique for measuring lower oesophageal pressure. Gastroenterolgy 1975; 68: 437-43.

7 Hobsley M, Silen W. Use of an inert marker (phenol red) to improve accuracy in gastric secretion studies. Gut 1969; 10: 787-95.

8 Faber RG, Russell RCG, Royston CMS, Whitfield P, Hobsley M. Duodenal reflux during insulin stimulated secretion. Gut 1974; 15: 880-4.

9 Venables CW. The value of a combined pentagastrin/ insulin test in studies of stomal ulceration. Br J Surg 1970; 57: 757-61.

10 Dodds WJ, Hogan WJ, Miller WN, Stef JJ, Arndorfer RC, Lydon SB. Effect of increased intra-abdominal pressure on lower oesophageal sphincter pressure. Dig Dis 1975; 20: 298-308.

11 Greaney MG, Irvin TT, Chattopadhyay DK. The measurement of resting and stimulated lower oesophageal sphincter pressure using the rapid pull through technique of oesophageal manometry. Scand J Gastroenterol 1978; 13: 799-806.

12 Mann CV, Hardcastle JD. The effect of vagotomy on the human gastro-oesophageal sphincter. Gut 1968; 9: 688-95.

13 Thomas PA, Earlam RJ. The gastro-oesophageal junction before and after operations for duodenal ulcer. Br J Surg 1973; 60: 717-9.

14 Khan TA. Effect of proximal gastric vagotomy on the canine lower oesophageal sphincter. Am J Surg 1981; 141: 219-21. 